Rapid high-performance liquid chromatography determination of tocopherols and tocotrienols in cereals

Engelsen, Merete Møller; Hansen, Åse Solvej

Published in:

Cereal Chemistry

DOI:

10.1094/CCHEM-85-2-0248

Publication date:

2008

Document version

Publisher's PDF, also known as Version of record

Citation for published version $(A P A)$ :

Engelsen, M. M., \& Hansen, A. S. (2008). Rapid high-performance liquid chromatography determination of tocopherols and tocotrienols in cereals. Cereal Chemistry, 85(2), 248-251. https://doi.org/10.1094/CCHEM-85-20248 


\title{
Rapid High-Performance Liquid Chromatography Determination of Tocopherols and Tocotrienols in Cereals
}

\author{
Merete Møller Nielsen ${ }^{1}$ and Åse Hansen ${ }^{1,2}$
}

\section{ABSTRACT}

Cereal Chem. 85(2):248-251

A rapid normal-phase high-performance liquid chromatography (NPHPLC) method has been developed for rapid determination of the total content of tocopherols (T) and tocotrienols (T3) in cereals. The new method uses a one-step extraction followed by NP-HPLC coupled with a fluorescence detector. The new method provides a baseline separation of the critical peaks of beta-tocotrienol $(\beta-\mathrm{T} 3)$ and gamma-tocopherol $(\gamma-\mathrm{T})$ within a short time of analysis. The extraction step requires no saponification step or addition of antioxidant. Addition of butylated hydroxytoluene (BHT) had no effect on the stability of vitamin E during sampling. The recovery was $96-100 \%$. The method is demonstrated by successful quantification of vitamin $\mathrm{E}$ in barley, wheat, and spelt grains, as well as wheat germ and flours from wheat, spelt, and rye.
Inherent vitamin $\mathrm{E}$ is an important antioxidant in foods and is composed of eight naturally occurring isomers: four tocopherols $(\alpha-\mathrm{T}, \beta-\mathrm{T}, \gamma-\mathrm{T}$, and $\delta$-T) and four tocotrienols $(\alpha-\mathrm{T} 3, \beta-\mathrm{T} 3, \gamma-\mathrm{T} 3$, and $\delta$-T3). The molecular structure of vitamin $\mathrm{E}$ consists of a polar chromanol ring linked to an isoprenoid chain (Fig. 1). The structure of tocotrienols differs from that of tocopherols by the presence of three trans double bonds in the hydrocarbon chain. In addition, $\alpha, \beta, \delta$, and $\gamma$ species of both tocopherols and tocotrienols differ with regard to the number and position of methyl groups on the chromanol ring (Fig. 1). $\gamma$-T and $\beta$-T3 differ very little in structure and molecular weight and are therefore difficult to separate chromatographically within a short time of analysis.

Cereals are rich sources of vitamin E, but the content and composition differ strongly from cereal to cereal and from endosperm to bran. The total amount of vitamin $\mathrm{E}$ is expressed in total equivalents based on biological activity (TE), which is an expression based on the activity relative to the naturally occurring, most active form of the vitamin, $\alpha$-tocopherol. TE in food is calculated by adding up all amounts of vitamin $\mathrm{E}$ after multiplying the amount of $\alpha$-T by $1.0, \beta$-T by $0.5, \gamma-\mathrm{T}$ by $0.1, \delta$-T by $0.03, \alpha-\mathrm{T} 3$ by $0.3, \beta-\mathrm{T} 3$ by 0.05 , and $\gamma-\mathrm{T} 3$ by 0.01 (Eitenmiller and Lee $2004 \mathrm{~b}$ ). The $\mathrm{mg}$ of $\alpha$-TE of cereals has been reported in other studies and was, for example, found to be 23.8 for whole grains of wheat (Panfili et al 2003), 15.0 for rye (Zielinski et al 2001), 14.9 for durum wheat (Panfili et al 2003), 10.6 for oat (Bryngelsson et al 2002), 10.8 for einkorn (Hidalgo et al 2006), 9.8 for maize (Panfili et al 2003), and 4.8 TE for rice (Sheppard et al 1992).

The importance of knowing the exact composition of vitamin $\mathrm{E}$ in the food is underlined by the fact that different studies have shown that tocopherols other than the omnipresent $\alpha$-tocopherol might have a significant effect on different biological activities such as disease prevention. When the only difference in the molecular structures is the presence of three double bonds in the phytyl side chain, some of the differences in health benefits could be due to the 3'trans, 7'trans configuration (Drotleff and Ternes 1999). Examples of health benefits of vitamin $E$ other than $\alpha-T$ is the $\gamma$-T and T3, which are reported to be highly effective in preventing cancer-related processes (Nesaretnem et al 1995; Qureshi et al 2000, 2001; Saldeen and Saldeen 2005; Brigelius-Flohé 2006; Nesaretnem et al 2007), Alzheimer's disease (Saldeen and Saldeen 2005), and cardiovascular diseases (Traber 2001; Nesaretnem et al 2007). Some methods reported do not separate the two critical peaks, and the content of $\beta$-T3 and $\gamma$-T is just reported

\footnotetext{
${ }^{1}$ University of Copenhagen, Faculty of LIFE Sciences, Department of Food Science, Quality \& Technology, Rolighedsvej 30, DK-1958 Frederiksberg C, Denmark ${ }^{2}$ Corresponding author: aah@life.ku.dk
}

doi:10.1094/CCHEM-85-2-0248

(c) 2008 AACC International, Inc. as a double peak (Lee et al 2004; Chen and Bergman 2005). When operating with a method that is not able to predict the exact composition of the vitamin E, mismatches are seen in the literature, because the reported composition often is high in $\gamma$-T content but no content of $\beta$-T3 (Lee et al 2004; Bustamante-Rangel et al 2007). That is in contrast to most findings for wheat and rye. For a full evaluation of possible health benefits in nutritional studies of cereals it is important to be able to evaluate all eight vitamin $\mathrm{E}$ isomers.

A new rapid method was developed to determine the total content and composition of vitamin $\mathrm{E}$ in different cereals and cereal products. The method is a one-step extraction followed by NPHPLC coupled with a fluorescence detector. The method's primary attribute is the ability to separate $\beta$-tocotrienol from $\gamma$ tocopherol within a short and acceptable time of analysis.

\section{MATERIALS AND MEHODS}

The extraction method used for extraction of vitamin $\mathrm{E}$ from cereals is slightly modified from the method described by Murkovic et al (2004). The modifications of the extraction method including a reduction in extraction time from $30 \mathrm{~min}$ to $10 \mathrm{~min}$ and no use of drying agent because the hexane used before was replaced with a dried hexane (Murkovic et al 2004). Standard solutions were measured both by the earlier NP-HPLC method
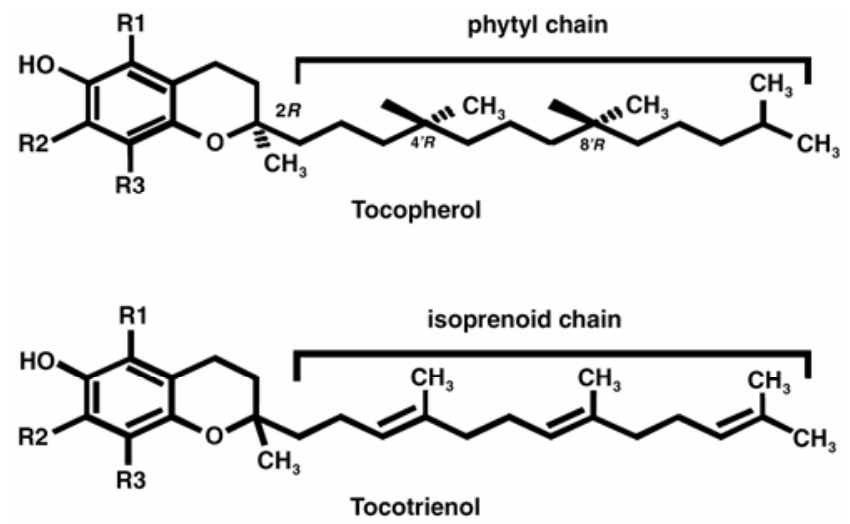

Four isoforms of tocopherols and tocotrienols:

$$
\begin{array}{llll}
\alpha-: & \mathbf{R}_{1}=\mathbf{C H}_{3} & \mathbf{R}_{2}=\mathbf{C H}_{3} & \mathbf{R}_{3}=\mathbf{C H}_{3} \\
\beta-: & \mathbf{R}_{1}=\mathbf{C H}_{3} & \mathbf{R}_{2}=\mathbf{H} & \mathbf{R}_{3}=\mathbf{C H}_{3} \\
\gamma-: & \mathbf{R}_{\mathbf{1}}=\mathbf{H} & \mathbf{R}_{\mathbf{2}}=\mathbf{C H}_{3} & \mathbf{R}_{3}=\mathbf{C H}_{3} \\
\delta-: & \mathbf{R}_{\mathbf{1}}=\mathbf{H} & \mathbf{R}_{\mathbf{2}}=\mathbf{H} & \mathbf{R}_{3}=\mathbf{C H}_{3}
\end{array}
$$

Fig. 1. Molecular structure of vitamin E. Tocopherols and tocotrienols in four different forms $(\alpha, \beta, \gamma$, and $\delta)$. 
used at our laboratory and by the improved NP-HPLC method. The former method used was modified from a method described by Dionisi et al (1995). Cereal samples are only analyzed by the improved NP-HPLC method.

\section{Chemicals}

Tocopherols $(\alpha-, \beta-, \gamma-, \delta$-tocopherol) and tocotrienols $(\alpha-, \beta-$, $\gamma-, \delta$-tocotrienols) of a purity $>95 \%$ were purchased as isomer kits from VWR (Copenhagen, Denmark). $n$-Hexane, acetic acid, and ethyl acetate were all of analytical grade and purchased from Sigma-Aldrich (Copenhagen).

\section{Standard Solutions}

The standard stock solutions of tocopherol and tocotrienol were prepared to a concentration of $500 \mu \mathrm{g} / \mathrm{mL}$ in hexane. The solution was stored at $-20^{\circ} \mathrm{C}$ for up to three months. The concentrations of the standard solutions were confirmed spectrophotometrically by evaporation of $2 \mathrm{~mL}$ of the solution under nitrogen and redilution in ethanol. Calculations of actual concentrations were made by using known extinction coefficients of each vitamin isomer in ethanol (Podda et al 1996). A calibration curve for all eight isomers was prepared over the concentration range of $1.0-25.0$ $\mu \mathrm{g} / \mathrm{mL}$. The detection limit for all eight isomers was $\approx 0.4 \mu \mathrm{g} / \mathrm{mL}$.

\section{Samples}

Whole grains of wheat, barley and spelt and flour samples of wheat, spelt, and rye were ground to a particle size $<0.5 \mathrm{~mm}$. The samples were harvested in 2005 and obtained from two mills: Lantmännen $\mathrm{A} / \mathrm{S}$ and Aurion $\mathrm{A} / \mathrm{S}$, which use different varieties. The samples were kept at $-4^{\circ} \mathrm{C}$ until analysis in plastic bags.

\section{Preparation of Extracts}

Finely milled sample $(1 \mathrm{~g})$ was extracted with $30 \mathrm{~mL}$ of hexane in a brown flask with a screw cap to avoid excessive exposure to light and air. The flasks were placed in an ultrasound bath for 10 min. The supernatant was quantitatively transferred to a brown flask and evaporated to dryness under nitrogen and dissolved in 3
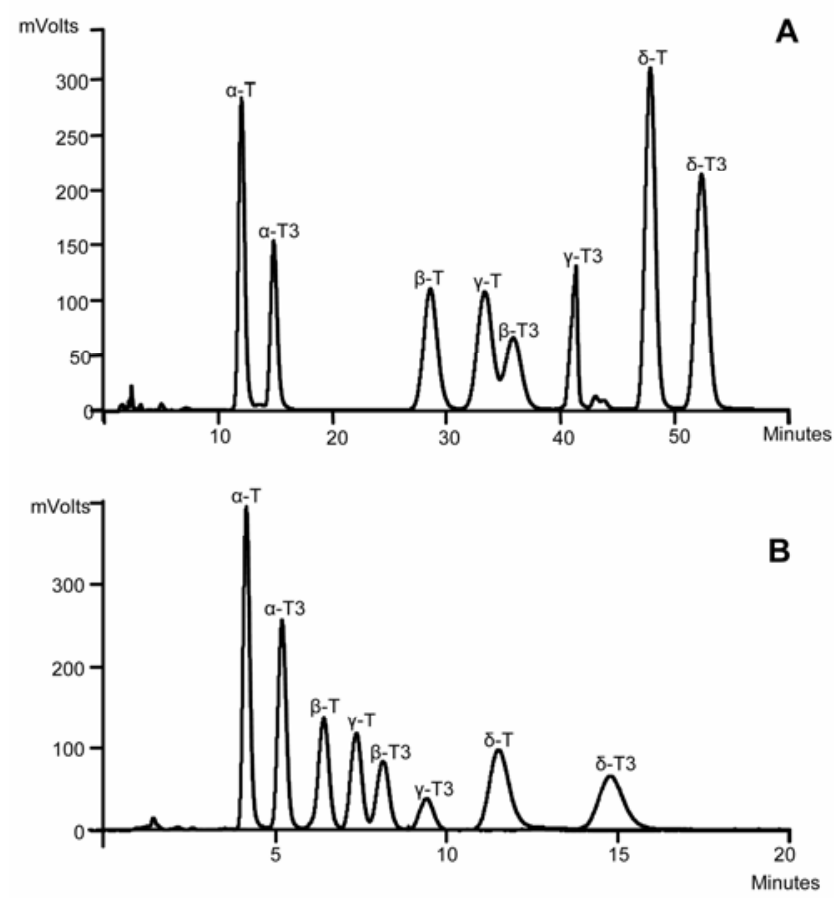

Fig. 2. Chromatogram of a standard solution $(20 \mu \mathrm{g} / \mathrm{g})$ measured by A) the formerly used method with a total analysis time of $60 \mathrm{~min}$; and $\mathbf{B}$ ) the optimized method with a total analysis time of $20 \mathrm{~min}$.
$\mathrm{mL}$ of hexane. All extracts were made in triplicate. Before injection onto the HPLC column, the extract was filtered through a $0.45-\mu \mathrm{m}$ filter.

\section{Instrumentation}

A Varian model (Star 9012) high-performance liquid chromatograph, equipped with a fluorescence detector (model 9070) was used. The detector was set to an excitation wavelength of $290 \mathrm{~nm}$ and an emission wavelength of $330 \mathrm{~nm}$.

\section{Chromatographic Conditions}

For the earlier method, the mobile phase consisted of hexane and 2-propanol at a flow rate of $1.0 \mathrm{~mL} / \mathrm{min}$ (Dionisi et al 1995). The program of A gradient was 0-10 min with hexane 2\% 2propanol (95:5); 10-15 min with hexane 2\% 2-propanol (90:10); 15-20 min with hexane 2\% 2-propanol (87:13); and finally 20-60 min with hexane $2 \%$ 2-propanol (87:13).

For the new method, the mobile phase consisted of $94.6 \%$ hexane, $3.6 \%$ ethyl acetate, and $1.8 \%$ acetic acid, and the flow rate of the mobile phase was set at $1.0 \mathrm{~mL} / \mathrm{min}$.

The quantitative HPLC separation for both methods was performed on a LiChrosorb Si $60(125 \times 4 \mathrm{~mm}$, i.d., particle size 5 $\mu \mathrm{m})$ normal-phase column, protected with a steel guard column $(50 \times 3 \mathrm{~mm}$, i.d., particle size $5 \mu \mathrm{m})$ filled with ChromGuard $\mathrm{S}$ (Bie \& Berntsen, Copenhagen, Denmark). The temperature of the column oven was $25^{\circ} \mathrm{C}$.

\section{Quantification of Tocopherol and Tocotrienol \\ in Cereal Samples}

The tocopherols and tocotrienols were identified by retention time and quantified by use of linear regression from the calibration curve.

\section{RESULTS AND DISCUSSION}

In all cereal test applications, the new NP-HPLC method resulted in good baseline separation of all eight analytes, which is a major improvement in particular on the very reliable separation of the $\beta$-T3 and $\gamma$-T peak.

\section{Differences in Total Analysis Time and Separation Between the Two Methods}

The total time of analysis is decreased by a factor of 3 (from 60 min to $20 \mathrm{~min}$ ) (Fig. 2). When analyzing known samples without delta isomers of vitamin $\mathrm{E}$, the time could be further reduced by 8 min to a total analysis time of $12 \mathrm{~min}$.

The long analysis time for the earlier method was due to the need to separate the $\beta$-tocotrienol and $\gamma$-tocopherol peaks. With the parameters used, such as mobile phase (hexane and 2-propanol), column temperature, and flow rate, it was not possible to further decrease the time of analysis and still obtain a satisfactory separation. The use of a gradient program for variable concentrations of mobile phase did not improve separation further. For this

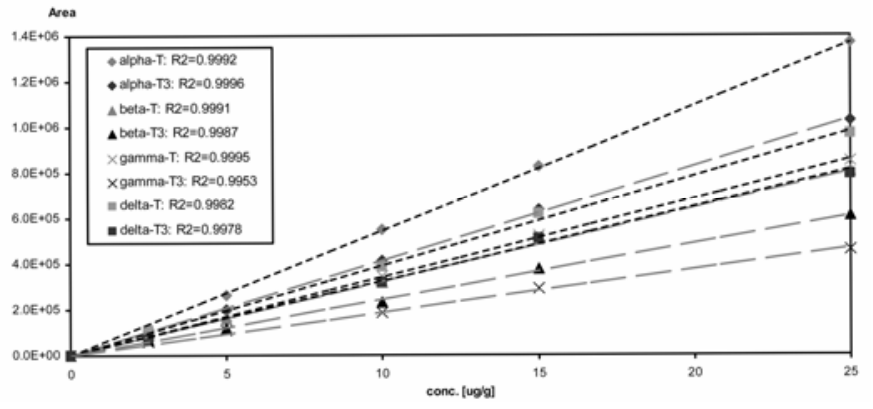

Fig. 3. Standard curves for all eight vitamin E isomers. 

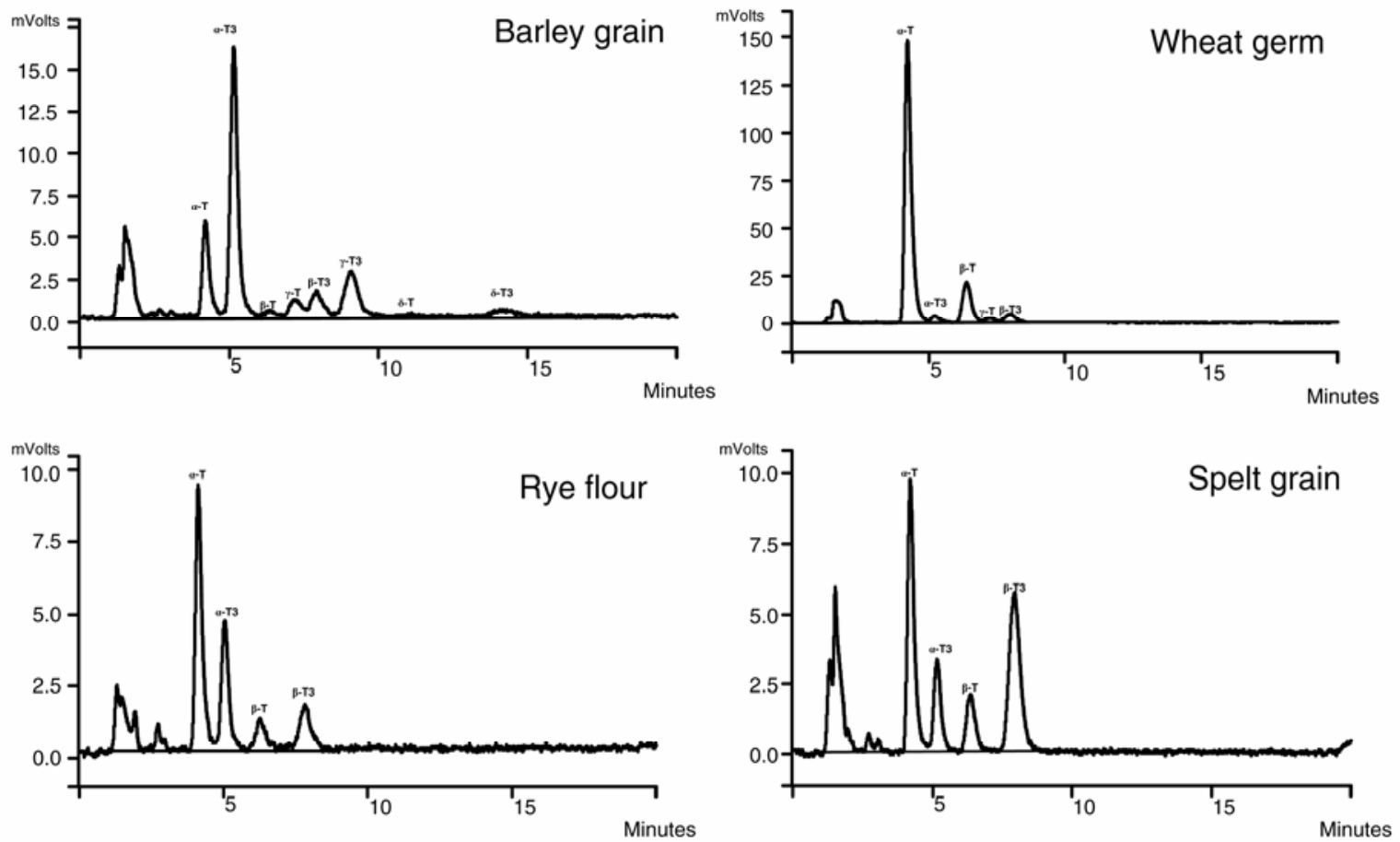

Fig. 4. Chromatograms of barley and spelt grains, rye flour, and wheat germ. Different peaks identified by retention times according to retention times of standard solutions.

reason, a mobile phase consisting of hexane, ethyl acetate, and acetic acid with the higher polarity was tested with good results. Also, the effect of lowering the column temperature and slowing the flow rate to a minimum was examined and resulted in a better separation. Figure 2B shows that the resulting method provides fine separation of the two critical peaks. The new method now allows, with high certainty, determination whether it is a $\beta-\mathrm{T} 3$ or a $\gamma$-T that is present in the cereal sample.

\section{Validation of the Optimized Method}

Linearity of the analysis was assessed for all eight vitamin $\mathrm{E}$ isomers in the concentration of $1.0-20.0 \mu \mathrm{g} / \mathrm{mL}$. The results are shown in Fig. 3.

Retention time of each of the eight peaks varied less then $\approx 0.2$ sec during a period of one year. This is to be compared with a retention difference between the two critical isomers $\beta$-T3 and $\gamma$ $\mathrm{T}$ of $\approx 0.8 \mathrm{~min}$, providing a good margin of reliability for the identification of the two critical isomers in cereal samples.

The extraction method was evaluated by recovery experiments of standard compounds. Three different known amounts $(2,4$, and $7 \mu \mathrm{g} / \mathrm{mL}$ ) of $\gamma$-tocotrienol were added to a sample of wheat where it is known that $\gamma$-tocotrienol is not present and analyzed in triplicate by the optimized NP-HPLC method. Recoveries were in the range of $96-100 \%$ with a trend of full recovery toward larger concentrations.

\section{Analysis of Cereal Samples}

Extraction of vitamin E can be difficult because it is very sensitive to light and oxygen. Vitamin $\mathrm{E}$ is a fat-soluble vitamin and often a saponification step has been used before extraction to get all vitamin E out of the grains (Panfili et al 2003; Franke et al 2007). However, in this study, nothing was gained by this step for wheat and rye, possibly because of the increased exposure to oxygen and because of the low content of lipids (2-3\%) in the cereals. The extraction procedure was also tested, including addition of BHT (data not shown). BHT is an antioxidant that is assumed to decrease the rate of oxidation of vitamin $\mathrm{E}$ during extraction, but because no oxidation occurred because of the short time of extraction, no affect of BHT was observed. This is in good agreement with a former study, where no effect of BHT as well was observed (Håkansson et al 1987).

After careful optimization, the extraction and NP-HPLC method was demonstrated by application to a set of various cereal samples for identification and quantification of vitamin $\mathrm{E}$ isomers. Different types of grains and milled products as whole wheat meal flour, which include bran and germ, and low extraction flour without bran and germ, were analyzed (Fig. 4). The identification was made by the retention time, which throughout this study was very reproducible. The quantification of the individual vitamin $E$ isomers was calculated by the use of calibration curves for all eight isomers. The results of the analysis are shown in Table I and it is readily observed that the content and composition of vitamin $E$ varies strongly from cereal to cereal and from product to product.

The total content of vitamin $\mathrm{E}$ in wheat, barley, and spelt grains varies from 12.7 to $22.5 \mathrm{TE}$, with the highest content in whole wheat grains. The content measured in this study differ both higher and lower in content than other studies (Balz et al 1993; Panfili et al 2003; Franke et al 2007; Zielinski et al 2007), presumably due to a significant variance in genotype and environmental effects.

The composition of vitamin $\mathrm{E}$ that is represented in the grains is very different. The measured wheat, spelt, and rye flours only contain $\alpha$ and $\beta$ forms of vitamin $\mathrm{E}$, whereas the barley grains contain all eight vitamin $\mathrm{E}$ forms, which is in agreement with earlier studies (Wang et al 1993; Panfili et al 2003; Eitenmiller and Lee 2004a; Michalska et al 2007). From Table I, it is also observed that the most predominant vitamin $\mathrm{E}$ in barley grains are $\alpha-\mathrm{T} 3$ and $\gamma-\mathrm{T} 3$, which are found in much higher levels than in any of the other measured samples. In contrast, $\beta-\mathrm{T}$ and $\beta-\mathrm{T} 3$ are found at much lower levels compared with wheat and spelt. Wheat germ has a high content of $\alpha-\mathrm{T}$ and $\beta-\mathrm{T}$ and is an excellent source of vitamin $\mathrm{E}$. When grinding grains into flour, the content of vitamin $\mathrm{E}$ is decreased. This is most pronounced for the tocotrienols, which are primarily located in the bran (Bryngelsson et al 2002; Eitenmiller and Lee 2004a; Zielinski et al 2007). 
TABLE I

Content of Tocopherols and Tocotrienols in Different Barley, Wheat, Spelt, and Rye Products

\begin{tabular}{|c|c|c|c|c|c|c|c|c|c|}
\hline \multirow[b]{2}{*}{ Product $(n=3)$} & \multicolumn{4}{|c|}{ Tocopherol Content in $\mu \mathrm{g} / \mathrm{g}$ of $\mathrm{dm}$} & \multicolumn{4}{|c|}{ Tocotrienol Content in $\mu \mathrm{g} / \mathrm{g}$ of $\mathbf{d m}$} & \multirow{2}{*}{$\begin{array}{c}\text { Total Vitamin E } \\
\text { Equivalent }(\mathrm{mg} \text { of } \alpha \text {-TE) }\end{array}$} \\
\hline & $\alpha-T$ & $\beta-\mathbf{T}$ & $\gamma-\mathbf{T}$ & $\delta-\mathbf{T}$ & $\alpha-\mathbf{T 3}$ & $\beta$-T3 & $\gamma-\mathbf{T 3}$ & $\delta$-T3 & \\
\hline Wheat germ & 177.7 & 65.0 & Trace & & 2.6 & 15.6 & & & 211.7 \\
\hline Whole wheat grain & 15.2 & 7.8 & & & 6.2 & 30.9 & & & 22.5 \\
\hline Wheat flour & 9.6 & 4.5 & & & 3.0 & 15.7 & & & 13.6 \\
\hline Whole meal wheat flour & 11.4 & 4.3 & & & 3.5 & 23.1 & & & 15.8 \\
\hline Whole spelt grain & 9.2 & 8.9 & & & 4.6 & 19.6 & & & 16.0 \\
\hline Spelt bran & 8.9 & 4.0 & & & 7.3 & 26.2 & & & 14.4 \\
\hline Spelt flour & 8.0 & 3.9 & & & 4.2 & 19.9 & & & 12.5 \\
\hline Whole meal spelt flour & 9.2 & 3.9 & & & 5.1 & 20.2 & & & 13.5 \\
\hline Rye flour & 9.4 & 2.5 & & & 7.1 & 5.8 & & & 13.0 \\
\hline Whole barley grain & 5.4 & 0.5 & 1.7 & 0.4 & 22.0 & 3.0 & 15.5 & 2.3 & 12.7 \\
\hline
\end{tabular}

\section{CONCLUSIONS}

This improved method has proven extraordinarily reproducible and effective for determination of tocopherols and tocotrienols in cereals. However, the main attribute of the method is the fine separation of the $\beta$-tocotrienol and $\gamma$-tocopherol peaks. The results obtained demonstrate that the outlined extraction method combined with the HPLC method is very useful for exploration of the vitamin $\mathrm{E}$ isomer composition in cereals and cereal product, which may be of great importance when discussing health issues of cereal products.

\section{ACKNOWLEDGMENTS}

We want to thank laboratory technician Mehdi Farahani for helping with the HPLC equipment and Gilda Kischinovsky for proofreading this manuscript. Lantmännen $\mathrm{A} / \mathrm{S}$ and Aurion $\mathrm{A} / \mathrm{S}$ are also acknowledged for samples.

\section{LITERATURE CITED}

Balz, M. K., Schulte, E., and Their, H. P. 1993. Simultaneous determination of alpha-tocopheryl acetate, tocopherols and tocotrienols by HPLC with fluorescence detection in foods. Fat Sci. Technol. 95:215-220.

Brigelius-Flohé, R. 2006. Bioactivity of vitamin E. Nutr. Res. Rev. 19:174-186.

Bryngelsson, S., Dimberg, L. H., and Kamal-Eldin, A. 2002. Effects of commercial processing on levels of antioxidants in oats (Avena sativa L.). J. Agric. Food Chem. 50:1890-1896.

Bustamante-Rangel, M., Delgado-Zamarreño, M. M., Sánchez-Pérez, A., and Carabias-Martínez, R. 2007. Determination of tocopherols and tocotrienols in cereals by pressurized liquid extraction-liquid chromatography-mass spectrometry. Anal. Chim. Acta 587:216-221.

Chen, M.-H., and Bergman, C. J. 2005. A rapid procedure for analysing rice bran tocopherol, tocotrienol and $\gamma$-oryzanol contents. J. Comp. Anal. 18:139-151.

Dionisi, F., Prodolliet, J., and Tagliaferri, E. 1995. Assessment of olive oil adulteration by reversed-phase high-performance liquid chromatography/amperometric detection of tocopherols and tocotrienols. J. AOAC 72:1505-1511.

Drotleff, A. M., and Ternes, W. 1999. Cis/trans isomers of tocotrienolsOccurrence and bioavailability. Eur. Food Res Technol. 210:1-8.

Eitenmiller, R., and Lee, J. 2004a. Food composition-Vitamin E. Pages 425-505 in: Vitamin E: Food Chemistry, Composition, and Analysis. R. Eitenmiller and J. Lee, eds. Marcel Dekker: New York.

Eitenmiller, R., and Lee, J. 2004b. Nutrition and Health Implications of Vitamin E. Pages 39-88 in: Vitamin E: Food Chemistry, Composition, and Analysis. R. Eitenmiller and J. Lee, eds. Marcel Dekker: New York.

Franke, A. A., Murphy, S. P., Lacey, R., Custer, L. J. 2007. Tocopherol and tocotrienol levels of foods consumed in Hawaii. J. Agric. Food Chem. 55:769-778.
Håkansson, B., Jägerstad, M., and Öste, R. 1987. Determination of Vita$\min \mathrm{E}$ in wheat products by HPLC. J. Micro. Anal. 3:307-318.

Hidalgo, A., Brandolini, A., Pompei, C., and Piscozzi, R. 2006. Carotenoids and tocols of einkorn wheat (Triticum monococcum ssp. monococcum L.). J. Cereal Sci. 44:182-193.

Lee, Y.-C., Oh, S.-W., Chang, J., and Kim, I.-H. 2004. Chemical composition and oxidative stability of safflower oil prepared from safflower seed roasted with different temperatures. Food Chem. 84:1-6.

Michalska, A., Ceglinska, A., and Zielinski, H. 2007. Bioactive compounds in rye flours with different extractions rates. Eur. Food Res. Technol. 225:545-551.

Murkovic, M., Piironen, V., Lampi, A. M., Kraushofer, T., and Sontag, G. 2004. Changes in chemical composition of pumpkin seeds during the roasting process for production of pumpkin seed oil. Part 1: Nonvolatile compounds. Food Chem. 84:359-365.

Nesaretnem, K., Guthrie, N., Chambers, A. F., and Carroll, K. K. 1995. Effect of tocotrienols on the growth of a human breast cancer cell line in culture. Lipids 30:1139-1143.

Nesaretnem, K., Yew, W. W., and Wahid, M. B. 2007. Tocotrienols and cancer: Beyond antioxidant activity. Eur. J. Lipid Sci. Technol. 109:445452.

Panfili, G., Fratianni, A., and Irano, M. 2003. Normal phase highperformance liquid chromatography method for the determination of tocopherols and tocotrienols in cereals. J. Agric. Food Chem. 51:39403944.

Podda, M., Weber, C., Traber, M. G., and Packer, L. 1996. Simultaneous determination of tissue tocopherols, tocotrienols, ubiquinols, and ubiquinones. J. Lipid Res. 37:893-901.

Qureshi, A. A., Mo, H., Packer, L., and Peterson, D. M. 2000. Isolation and identification of novel tocotrienols from rice bran with hypocholesterolemic, antioxidant, and antitumor properties. J. Agric. Food Chem. 48:3130-3140.

Qureshi, A. A., Peterson, D. M., Hasler-Rapacz, J. O., and Rapacz, J. 2001. Novel tocotrienols of rice bran suppress cholesterogenesis in hereditary hypercholesterolemic swine. J. Nutr. 131:223-230.

Saldeen, K., and Saldeen, T. 2005. Importance of tocopherols beyond $\alpha$ tocopherol: Evidence from animal and human studies. Nutr. Res. 25:877-889.

Sheppard, A. J., Pennington, J. A. T., and Weihrauch, J. L. 1992. Analysis and distribution of Vitamin E in vegetable oils and foods. Pages 9-31 in: Vitamin E in Health and Disease. L. Packer and J. Fuchs, eds. Marcel Dekker: New York.

Traber, M. G. 2001. Does Vitamin E decrease heart attack risk? Summary and implications with respect to dietary recommendations. J. Nutr. 131:395S-397S.

Wang, L., Xue, Q., Newman, R. K., and Newman, C. W. 1993. Enrichment of tocopherols, tocotrienols, and oil in barley fractions by milling and pearling. Cereal Chem. 70:499-501.

Zielinski, H., Ceglinska, A., and Michalska, A. 2007. Antioxidant contents and properties as quality indices of rye cultivars. Food Chem. 104:980-988.

Zielinski, H., Kozlowska, H., and Lewczuk, B. 2001. Bioactive compounds in the cereal grains before and after hydrothermal processing. Innovative Food Sci. Emerg. Technol. 2:159-169. 